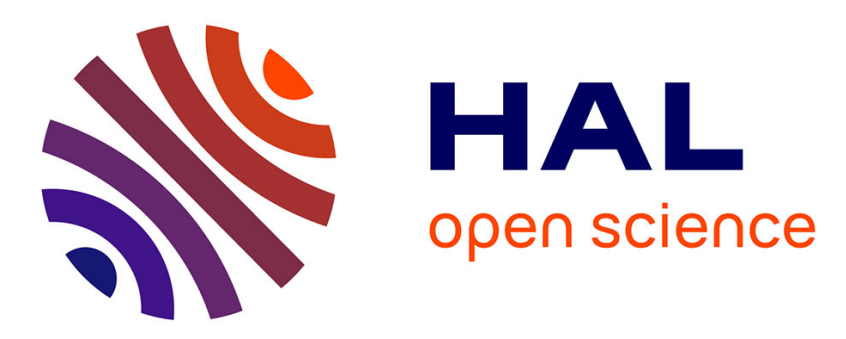

\title{
MISTIGRI instrumental concept for high-resolution thermal infrared imaging
}

\author{
Francesc Tintó Garcia Moreno, Guy Fargant, Frédéric Guérin, Claude \\ Israbian, Jean-Claude Mathieu, Joël Michaud, Alain Bardoux, Olivier \\ Hagolle, Jean-Pierre Lagouarde
}

\section{To cite this version:}

Francesc Tintó Garcia Moreno, Guy Fargant, Frédéric Guérin, Claude Israbian, Jean-Claude Mathieu, et al.. MISTIGRI instrumental concept for high-resolution thermal infrared imaging. SPIE Optics+Photonics, Aug 2009, San Diego, United States. 10.1117/12.825637 . hal-02756573

\section{HAL Id: hal-02756573 \\ https://hal.inrae.fr/hal-02756573}

Submitted on 3 Jun 2020

HAL is a multi-disciplinary open access archive for the deposit and dissemination of scientific research documents, whether they are published or not. The documents may come from teaching and research institutions in France or abroad, or from public or private research centers.
L'archive ouverte pluridisciplinaire HAL, est destinée au dépôt et à la diffusion de documents scientifiques de niveau recherche, publiés ou non, émanant des établissements d'enseignement et de recherche français ou étrangers, des laboratoires publics ou privés. 


\title{
MISTIGRI Instrumental concept for high resolution thermal infrared imaging
}

\author{
F. Tintó Garcia-Moreno*a, G. Fargant ${ }^{\mathrm{b}}$, F. Guerin ${ }^{\mathrm{b}}$, C. Israbian ${ }^{\mathrm{b}}$, JC. Mathieu ${ }^{\mathrm{b}}$, \\ J. Michaud ${ }^{a}$, A. Bardoux ${ }^{a}$, O. Hagolle ${ }^{a}$, J.P. Lagouarde ${ }^{c}$ \\ aCentre National d'Etudes Spatiales, 18 Avenue Edouard Belin, 31401 Toulouse Cedex 9, FRANCE; \\ bThales Alenia Space, 100 Boulevard du Midi, 06156 Cannes La Bocca, FRANCE; \\ 'INRA - UR1263 EPHYSE, 71 Avenue E. Bourlaux, 33140 Villenave d'Ornon, FRANCE
}

\begin{abstract}
High resolution images in the Thermal infrared provide a way to detect irrigated fields, to measure evapo-transpiration and detect plant water stress. Models and algorithms have largely improved to yield very good results. However the only inorbit satellites providing high resolution images in the thermal infrared domain (Landsat, Aster) are long beyond their design lifetime. Furthermore, they do not provide frequent acquisitions (1 image every 16 days for Landsat and Aster, while 1 image per couple of days would be required to monitor plant water stress). There is indeed a need for high resolution and high repetitivity thermal infrared data for hydrological applications.

CNES carried out a feasibility study of such a mission on a microsatellite. The mission is called MISTIGRI (MicroSatellite for Thermal InfraRed Ground Surface Imaging). The preliminary payload design was performed by Thales Alenia Space for CNES. An instrumental concept was proposed which fulfils the mission requirements. The study addressed both cooled and uncooled solutions, although a micro-bolometer detector was preferred after trade-off. This paper addresses the results of the MISTIGRI payload feasibility study; it presents the mission requirements, the proposed instrumental concept, describes the major subsystems and provides the preliminary performance budgets.
\end{abstract}

Keywords: Thermal Infrared, micro-bolometer, microsatellite, water budget, agriculture, hydrology

\section{INTRODUCTION}

\subsection{Mistigri Mission}

The surface temperature is a key parameter of the surface energy budget; it can be directly related to the surface energy fluxes, and particularly to the latent heat flux, i.e. evapo-transpiration (5 Courault et al., 2005 and 5 Kalma et al., 2008) and water stress (5 Boulet et al., 2007): when vegetation is not stressed by the lack of water, evapo-transpiration reduces its temperature, but when the plants are stressed, evapo-transpiration is reduced and their temperature increases. Measuring the temperature enables to measure the evapo-transpiration and the water stress. As the development of vegetation and agricultural crops is tightly related to the water status of plants and soil, measuring the surface temperature is particularly interesting for practical applications such as scheduling irrigation, or predicting yields for instance. The optimisation of water use is obviously needed for countries subject to dry climatic conditions with limited water resources, but also for environmental impacts, such as soil leaching and pollution of water tables. Other important applications can also be found, for instance in the field of urban climate where the surface temperature can provide information about the local climate (welfare of inhabitants, urban heat island, impact of heat waves, etc.) or the estimation of anthropogenic fluxes (5 Arnfield, 2003 and 5 Voogt and Oke, 2003). The context of climatic change now obviously makes all these applications even more crucial. The first priority of the proposed MISTIGRI mission is devoted to the monitoring of water conditions of agricultural crops and natural vegetation, but applications to other fields (urban and coastal areas) are also explored to enlarge the interest of the mission.

In most countries, the typical scale of the units of land use (size of fields and size of urban districts) and the natural heterogeneities (spatial variability of soil properties for instance) is around a few tens of meters (5 Kustas et al., 2004). The spatial resolution of satellite imagery must therefore be consistent with this scale. 
However, thermal infrared (TIR) remote sensing data combining both a high spatial resolution as well as a high frequency of revisit is not available on an operational basis today. Some instruments (MODIS, AATSR, AVHRR) do provide daily measurements but only at kilometric resolution, which is usually much larger than the size of the fields. Such measurements are difficult to interpret and require disaggregation (5 Kustas et al., 2004 and 5 Agam et al., 2007) leading to important uncertainties on evapo-transpiration. The only space borne high resolution TIR instruments are TM/ETM and ASTER aboard Landsat 5/7 and Terra satellites respectively, but their 16 day repetitivity is not sufficient to enable a regular and operational monitoring of the hydric status of vegetation. Among the approved satellites, only the Landsat Data Continuity Mission (LDCM) will provide such measurements, but still with an insufficient repetitivity. MISTIGRI fills this gap by combining the interest of high spatial resolution TIR data with a revisit of 1 day or 2 days. MISTIGRI is designed to be a low cost mission, with a research strategy based on the observation of a network of experimental sites in the world, not on a global coverage basis. This strategy is similar to the one adopted for the Venus mission in the visible domain. If the mission is confirmed, MISTIGRI could be launched in 2015.

\subsection{Requirements}

MISTIGRI TIR resolution will be $50 \mathrm{~m}$, compatible with a typical field size and surface heterogeneities, with a minimum field of view of $25 \times 25 \mathrm{~km}$. Visible and near-infrared bands at $20 \mathrm{~m}$ resolution are also required to ease scene identification, derive land cover classifications, characterise the vegetation cover and disaggregate thermal infrared measurements. Lagouarde et al., 19955 have shown that TIR observations are also affected by directional effects: the temperature observed from a TIR sensor depends on sun and viewing angles, mainly because of shading effects. Directional anisotropy and hot spot phenomena up to $\pm 3^{\circ} \mathrm{C}$ and $10^{\circ} \mathrm{C}$ have been experimentally observed over cities ( 5 Lagouarde et al., 2008) and forests respectively, models have been developed. The impact of this anisotropy will be largely reduced and controlled thanks to MISTIGRI's sun-synchronous phased-orbit that enables to observe a given site every second day with a constant viewing angle, furthermore sun angles will only vary slowly throughout the seasons.

The TIR bands with priority 1 will be centred at $10.3 \mu \mathrm{m}$ and $11.5 \mu \mathrm{m}$. At least two bands are necessary to allow atmospheric correction using, for instance, a split window method (5 Sobrino et al., 1994). For these two bands, the emissivity ranges between 0.95 and 1 , and the radiative temperature can be converted into surface temperature using emissivity hypotheses from the characterisation of vegetation cover obtained in the visible and near-infrared (VNIR) bands. Alternatively, two extra TIR bands $(8.6 \mu \mathrm{m}$ and $9.1 \mu \mathrm{m})$ might be added to separate emissivity and temperature and thus estimate surface temperature with better accuracy (5 Schmugge et al., 2002). These bands are considered as bands of priority 2.

Adding a MWIR band centred at $3.7 \mu \mathrm{m}$ was considered because of its good sensitivity to detect fires. This band was finally not selected because the probability of observing a forest fire would be too low for a mission based on the only observation of fixed experimental sites.

Concerning the radiometric performances, the main question is the required NedT error (standard deviation of noise expressed in temperature unit). According to the present study, an instrumental NedT better than $0.1^{\circ} \mathrm{K}$ is difficult to reach for uncooled instruments. Furthermore, the overall performance on the determination of surface temperature after atmospheric and emissivity correction is not less than $1^{\circ} \mathrm{K}$ (5 Jacob et al., 2006). Moreover, directional effects and ergodicity effects (5 Lagouarde et al., 2000) further degrade the performance. It is thus not justified to ask for a NedT of $0.1^{\circ} \mathrm{K}$ at instrument level. MISTIGRI's NedT requirement is $0.5^{\circ} \mathrm{K}$, with a design goal at $0.2^{\circ} \mathrm{K}$.

Radiometric calibration is also an important issue. It must be compatible with the expected accuracy for surface temperatures; therefore absolute calibration requirement has been specified to $1^{\circ} \mathrm{K}$. Moreover, relative variations of calibration from one pixel to another or from two successive acquisitions of a same site would also increase the noise on time series. The relative calibration requirements for both detector equalisation as well as multi-temporal calibration have been set to the same values as NedT requirement: $0.5^{\circ} \mathrm{K}$, with a design goal at $0.2^{\circ} \mathrm{K}$. 


\section{INSTRUMENTAL CONCEPT}

The preliminary payload design was performed by Thales Alenia Space for CNES. The focus was put on the thermal infrared instrument which is the specificity of MISTIGRI mission. Several scenarios were considered including two different orbital altitudes, cooled or uncooled detectors, a full or reduced number of bands and the implementation or not of a pointing mirror. Based on the results of the preliminary design, CNES carried out a trade-off in order to select the preferred solution, taking into account technical, financial and managerial considerations. This paper will only address the preferred scenario.

\subsection{Preferred Scenario}

The selected instrumental concept is aimed to be compatible with the CNES microsatellite platform, Myriade, in its standard configuration. The key parameters defining this scenario are listed below:

\begin{tabular}{|c|c|c|c|}
\hline Parameter & \multicolumn{2}{|c|}{ Value } & Comment \\
\hline Orbit altitude & \multicolumn{2}{|c|}{$720 \mathrm{Km}$} & 2-day revisit phased orbit \\
\hline Line of Sight steering (roll) & \multicolumn{2}{|c|}{ Satellite } & No pointing mirror \\
\hline Spectral Bands & \multicolumn{2}{|c|}{$\begin{array}{l}10.3 \mu \mathrm{m} / 11.5 \mu \mathrm{m} / 8.6 \mu \mathrm{m} / 9.1 \mu \mathrm{m} \\
450 \mathrm{~nm} / 670 \mathrm{~nm} / 865 \mathrm{~nm} / 910 \mathrm{~nm}\end{array}$} & $\begin{array}{l}\text { TIR1 /TIR2 / TIR3 / TIR4 } \\
\text { Blue / Red / NIR1 / NIR2 }\end{array}$ \\
\hline \multirow[t]{2}{*}{ Swath width } & \multicolumn{2}{|c|}{$25 \mathrm{Km}$} & \\
\hline & VNIR & TIR & \\
\hline Resolution & $20 \mathrm{~m}$ & $50 \mathrm{~m}$ & \\
\hline Entrance pupil diameter & $80 \mathrm{~mm}$ & $270 \mathrm{~mm}$ & \\
\hline Focal length & $468 \mathrm{~mm}$ & $255 \mathrm{~mm}$ & \\
\hline Aperture & $\mathrm{F} / 7.8$ & $\mathrm{~F} / 0.94$ & \\
\hline Detector type & CCD 1D array & Micro-bolometer & Uncooled \\
\hline Imaging mode & Pushbroom & $\begin{array}{l}\text { Supermode } \\
\text { TDI-like binning }\end{array}$ & See $\S 2.2$ \\
\hline TDI-like images / lines & - & 8 & On-ground binning \\
\hline Smearing compensation & \multicolumn{2}{|c|}{1.5} & By satellite slow-down \\
\hline MTF@ Nyquist & $\geq 0.12$ & $\geq 0.12$ & See $\$ 4.1$ \\
\hline NedT@ 290K & - & $0.2 \mathrm{~K}$ to $0.6 \mathrm{~K}$ & See $\$ 4.2$ \\
\hline SNR@ minimum radiance & 70 to 180 & - & See $\$ 4.2$ \\
\hline Mass & \multicolumn{2}{|c|}{$68 \mathrm{Kg}$} & Including $20 \%$ margin \\
\hline Power consumption & \multicolumn{2}{|c|}{$\begin{array}{ll}\text { Imaging mode: } & 54 \mathrm{~W} \\
\text { Standby: } & 46 \mathrm{~W}\end{array}$} & Nominal, without margin \\
\hline
\end{tabular}

Table 1: Key parameters defining the preferred scenario

\subsection{TIR Imaging mode}

Low Earth orbit imaging satellites usually use what is called the "pushbroom" imaging mode. In such satellites a linear array detector is mounted in the focal plane, perpendicular to the satellite track, and acquires the signal from the scene, along the swath. The second dimension (along-track) is naturally provided by the satellite's orbital movement. The pixel pitch defines the ground sampling distance (GSD) and integration time. 
However, high resolution missions may need other technical solutions in order to achieve the required radiometric performances. Time Delay Integration (TDI) is a commonly used technique, whereby the signal of a ground pixel on the detector is continuously integrated over several lines in synchronisation with the satellite movement. Thus the signal of a ground pixel is increased, achieving a better signal to noise ratio (SNR). Another possibility is what is known as "supermode"; in this case the pixel footprint is bigger than the GSD thus over-sampling the scene. The supermode can be implemented in different ways; one possibility is to provide the payload with a two-dimension detector array which will be tilted at $45^{\circ}$ with respect to the satellite along-track direction.

The proposed TIR instrument combines the supermode concept with on-ground TDI-like binning. This solution leads to a compact instrument, compatible with Myriade and compliant with MISTIGRI's strict radiometric requirements. In this case the supermode is achieved by tilting the detector array at $45^{\circ}$ with respect to the satellite's along-track direction, as shown in Figure 1. One drawback of this solution is that the swath of the instrument is lower than if the detector were not tilted.

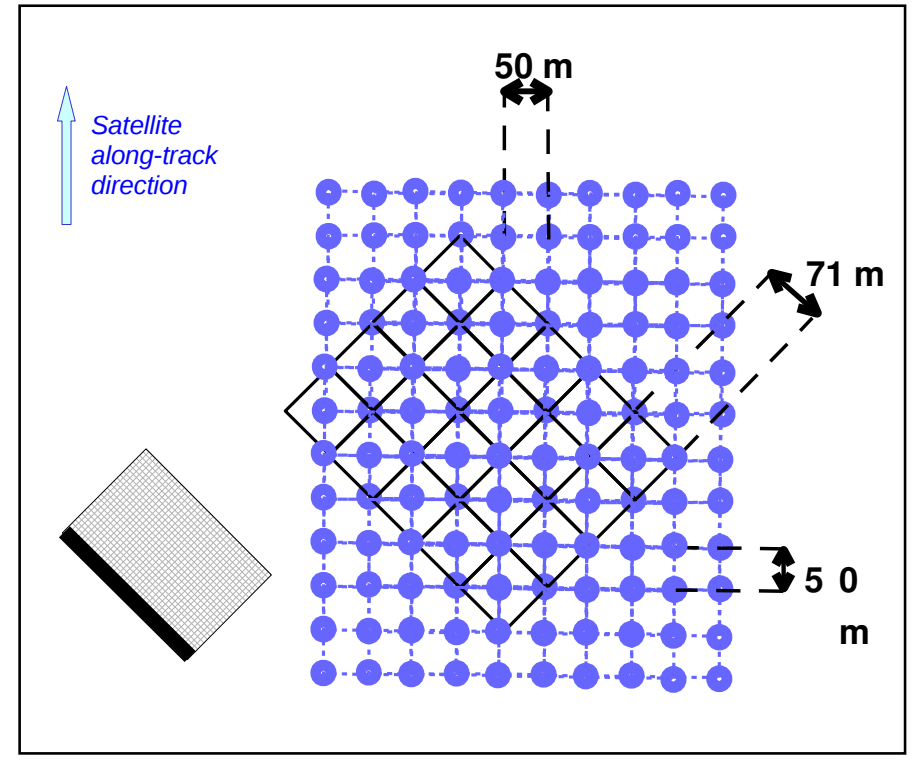

Figure 1: Supermode concept

Figure 1 shows the ground sampling grid (in blue) with a GSD of 50m. Super-imposed on it is the footprint of the detector array (in black). By tilting the detector, the ground footprint of each pixel is doubled, thus increasing the signal by a factor of 2. It can also be seen that with one detector read-out, only half of the pixels of an image line are acquired (every second pixel), thus two consecutive acquisitions are needed in order to complete the line as detailed in Figure 2.

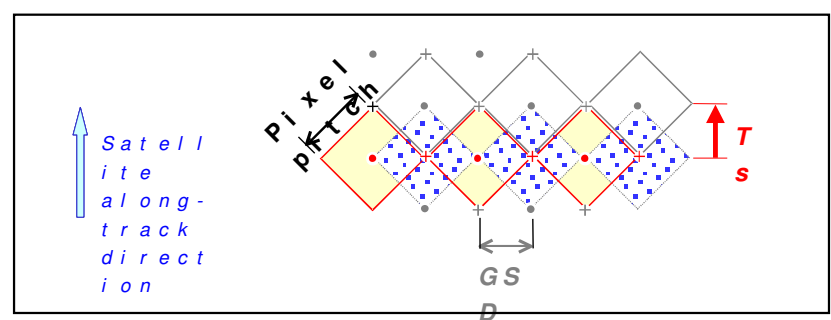

Figure 2: Detail of the line acquisition

Figure 2 shows that two detector read-outs are needed in order to complete a line: a first acquisition for the yellow pixels and a second one for the dotted ones. The two acquisitions are separated by a sampling time Ts corresponding to a $50 \mathrm{~m}$ satellite ground-footprint shift. 
Besides implementing the supermode, on-ground TDI-like binning is necessary to achieve the radiometric requirements with this instrumental concept. The idea consists of assigning several lines of the detector array to each band. Then, by acquiring several consecutive images synchronously with the satellite movement, the same scene pixel will be acquired several times, at each line of the detector. All these images will be downloaded and processed on-ground to produce the binned image with enhanced performances. As a result of a trade-off, the number of images used for the TDI-like binning was set to 8 .

\subsection{TIR Focal plane}

A French company called ULIS has developed a 640 x 480 micro-bolometer array with a pixel pitch of $25 \mu \mathrm{m}$. A trade-off was made, leading to the selection of this detector for the TIR instrument. Although the sensitivity of micro-bolometers is less than that of cryogenic detectors, such detectors have the main advantage that they do not need a cooling system. In addition, the ULIS detector has several features that are well adapted to the application, such as windowing capability or programmable gain.

It is important to note that the micro-bolometer thermal time constant introduces a constraint in the satellite operation. Indeed, the sampling time must be longer than the time constant in order to achieve good modulation transfer function (MTF) and linearity performances. According to the latest measurements on such detectors, the sampling time must be set between 1.5 to 2 times longer than the time constant, i.e. a minimum of $7.5 \mathrm{~ms}$ for the present case. In order to achieve this sampling time, satellite slow-down is needed when imaging. Given the orbit at $720 \mathrm{~km}$ altitude, the satellite slow-down has a factor of 1.5 .

The spectral selection is done by a thin-layer interference filter in front of the detector. The filters must be wide enough to acquire the same line of the scene 8 times, thus allowing on-ground TDI-like image binning. Furthermore, by tilting the detector from $45^{\circ}$, the useful swath (seen by all bands) is decreased. Given the filters' width and the minimum spacing between them, a design accommodating the 4 TIR bands in a unique detector would have a swath width smaller than the requirement. Therefore, in this configuration a focal plane with two micro-bolometer arrays is needed to provide both the 4 TIR bands as well as the required swath width. Figure 3 shows a focal plane configuration with 4 bands and a swath width of $\sim 25 \mathrm{~km}$ (500 pixels).

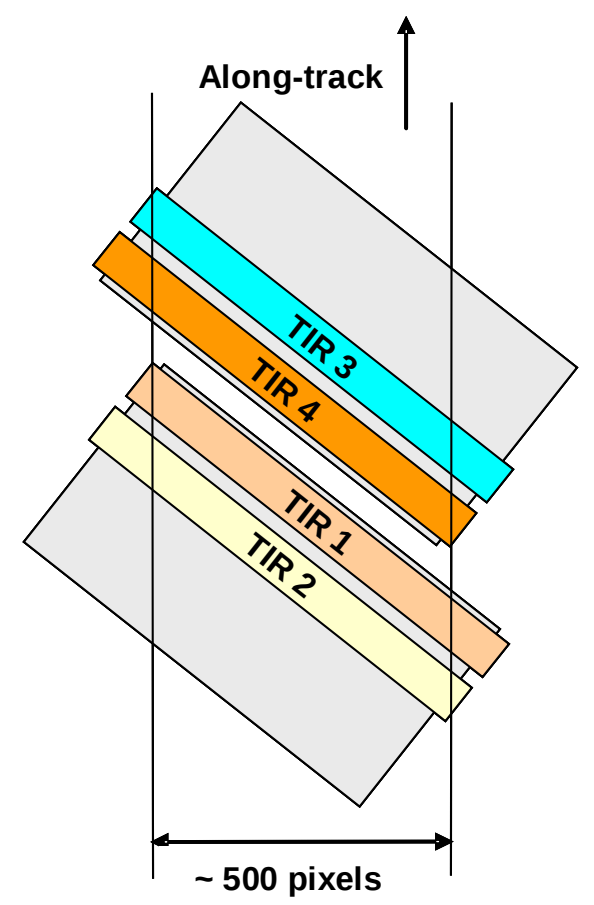

Figure 3: Focal plane configuration 


\subsection{TIR Optical layout}

The optical layout is shown in Figure 4. It consists of 4 lenses, one of them being aspheric. The entrance pupil is located in front of the back lenses (not at the front lens). The materials selected for the lenses are Germanium and ZnSe. They are chosen to ensure a good transmission and the aberration correction in the entire spectral domain. An alternative solution would be to use diffractive optics for one of the lenses.

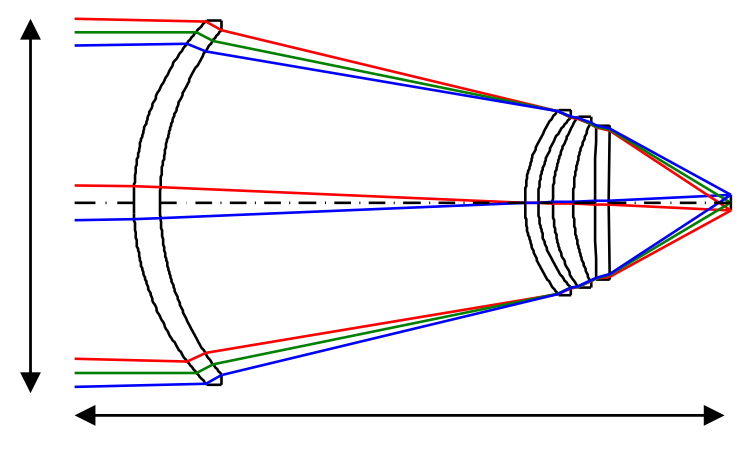

Figure 4: Optical layout

\subsection{Mechanical and thermal design}

The mechanical design of the instrument has taken into account the constraints imposed by the Myriade platform in its standard configuration.

The two cameras (VNIR and TIR) are mounted on a stable optical bench. They are secured to the optical bench by flexible blades which ensure mechanical and thermal decoupling. The payload is composed of the following main subassemblies: the VNIR optics and focal plane, the TIR optics and focal plane, three electrical units for payload control and video electronics of each camera, the TIR calibration subsystem and two radiators, one for the focal plane and the other for the electronics. A pointing mirror for cross-track image acquisition and calibration purposes was foreseen but rejected since it was impossible to accommodate it on the platform. A CAD view of the preliminary mechanical design is shown in Figure 5.

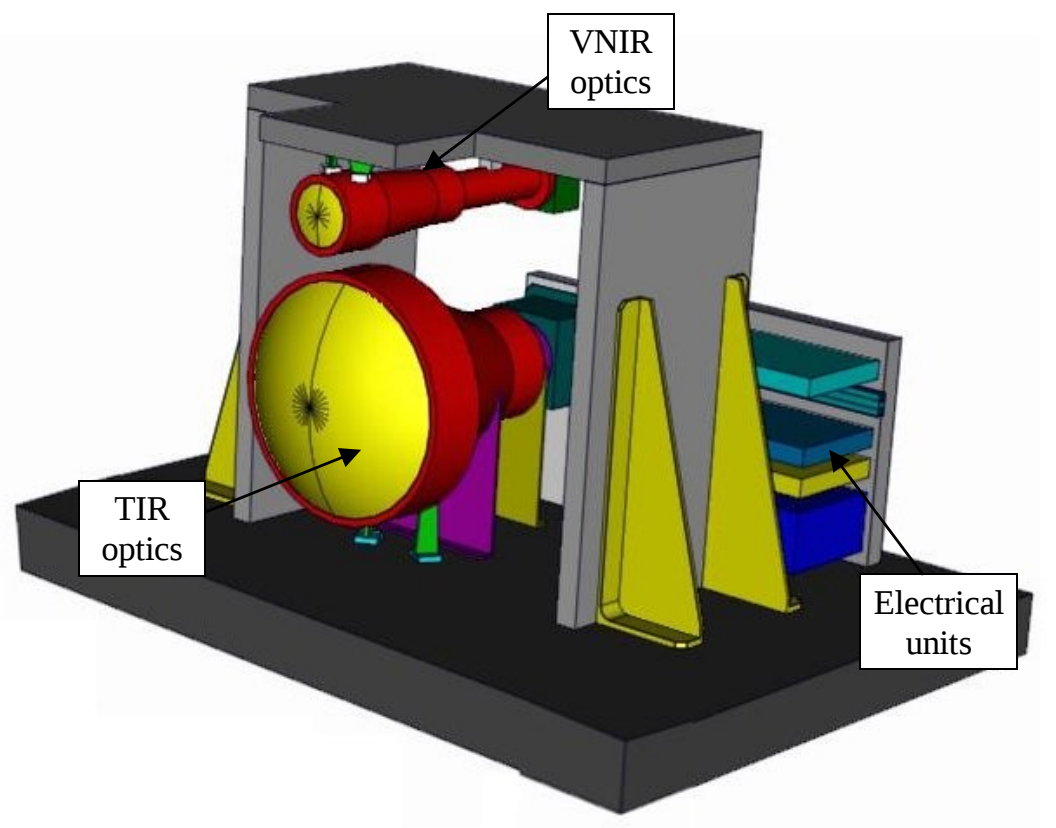

Figure 5: CAD view of the instrument 
The thermal design of the TIR instrument plays a key role in its performances. Radiative fluxes seen by the detector were modelled in order to establish a preliminary flux budget. The model was used to determine the radiometric sensitivity of the instrument to temperature fluctuations of the main subassemblies: front lens, back lens assembly and detector diaphragm. For each of these components, a requirement was set for temperature stability based on the radiometric sensitivity to their temperature variations. Table 2 shows the requirement in terms of temperature stability for each of the instrument's subassemblies. These figures are to be understood as the thermal stability between two consecutive calibrations.

\begin{tabular}{|l|c|}
\hline \multicolumn{1}{|c|}{ Subassembly } & Thermal stability requirement \\
\hline Micro-bolometer & $10 \mathrm{mK}$ \\
\hline Detector diaphragm & $20 \mathrm{mK}$ \\
\hline Back lenses assembly & $0.15 \mathrm{~K}$ \\
\hline Front lens & $1.3 \mathrm{~K}$ \\
\hline
\end{tabular}

Table 2: Thermal stability requirements

The feasibility of such a thermal control was verified by analogy to previous projects. The sensitivity analysis shows that the back lens assembly must be precisely regulated; it also shows that the radiometric performances of the instrument are not very sensitive to temperature variations in the front lens. Furthermore, the impact of such variations can be taken into account by the calibration in the case that it is precisely measured. The temperature variation of the front lens is $2.6 \mathrm{~K}$ during the orbital cycle. The temperature gradient along the lens thickness is very small.

\section{CALIBRATION}

An on-board calibration system is needed for the TIR instrument. A special effort was done to define the calibration method and frequencies, since they are a main driver in the instrument's radiometric performances. The proposed calibration method and frequencies are described in this paragraph.

\subsection{Calibration method}

Calibration systems for infrared instruments generally include blackbodies situated at the entrance of the instrument, so that the entire optical chain is calibrated. Given the size of MISTIGRI's TIR instrument, this solution would need a voluminous blackbody which would be incompatible with the Myriade platform. Instead, it is proposed to implement two blackbodies in front of an intermediate pupil placed next to the back lens assembly. A diagram of the calibration system is shown in Figure 6; this solution leads to a reduction in the size of the blackbodies. The drawback of this method is that the front lens is not taken into account by the calibration system. Thus the emissivity and transmission of the front lens need to be characterised on ground and, at a later stage, taken into account by the calibration method from fine measurements of the lens' in-flight temperature.

Two blackbodies at different temperatures of $283 \mathrm{~K}$ and $313 \mathrm{~K}$ are needed to calibrate the instrument and retrieve the gain and offset values to be applied during image processing. The calibration process should not disturb the thermal equilibrium of the instrument, specifically the temperature of the back lens assembly. Therefore, a quick mechanism is needed to slide the blackbodies in front of the optics and then remove them. Given the size and the mass of such blackbodies, it is assumed that the slide can be done in approximately 2 seconds. Furthermore, it is assumed that around 200 images of the blackbody will be acquired during a period of approximately 1.5 seconds. 


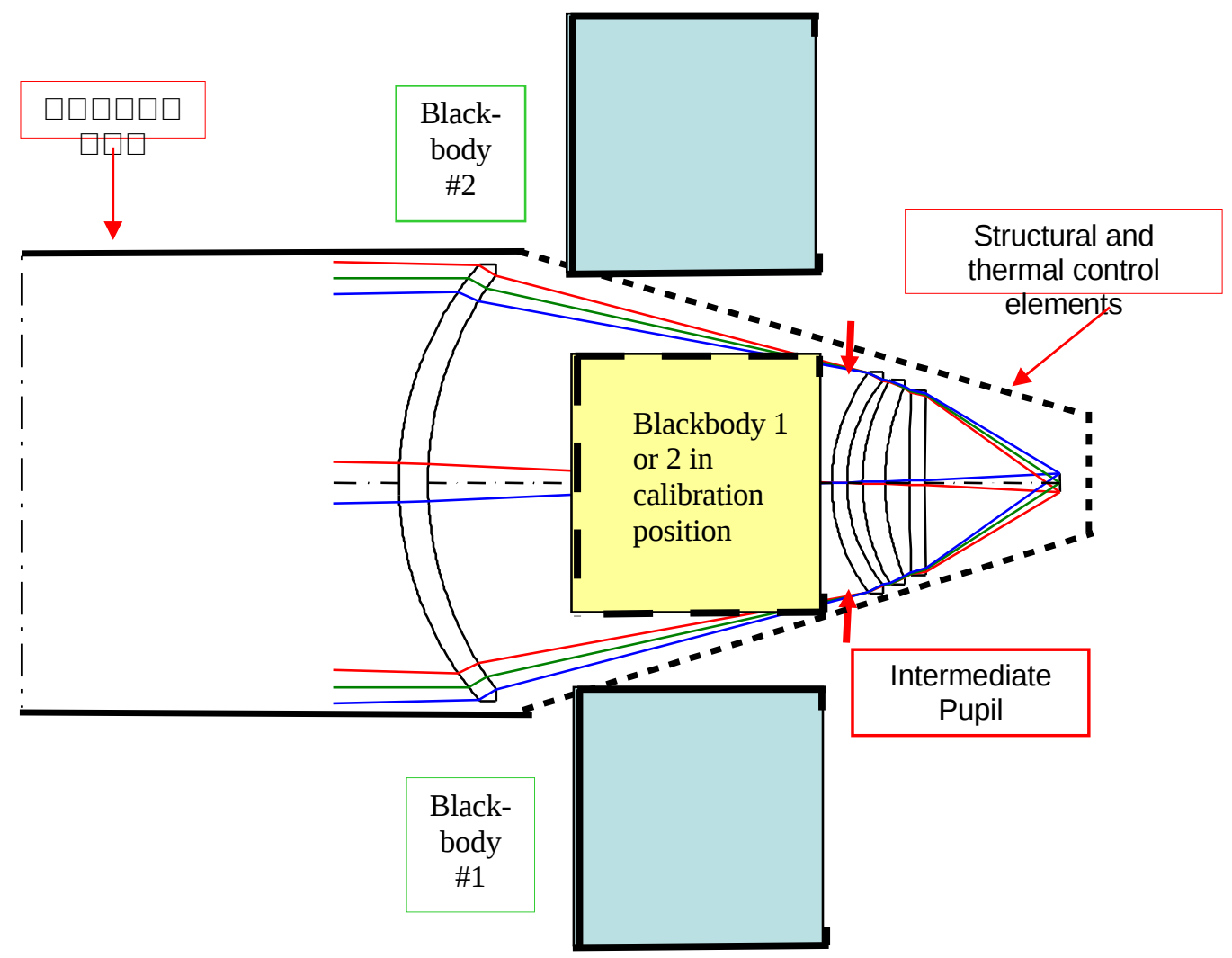

Figure 6: Calibration system diagram

In addition, deep space calibration is also needed in order to assess the optics' in-flight transmission and emissivity drift, throughout the satellite's lifetime. Since no folding mirror is incorporated into the design, deep space steering is achieved by satellite manoeuvring. This operation will certainly disturb the instrument's thermal equilibrium and therefore should not be performed frequently. The impact of deep space calibration was not the object of the present study and should be addressed in detail in the future.

\subsection{Calibration frequencies}

The frequency of blackbody calibration is directly linked firstly to the temperature stability that can be achieved by the thermal control and secondly to the timeframe of the diverse drifts, mainly due to the detector and video electronics. In order to determine the blackbody calibration frequency, all radiometric requirements were taken into account: NedT, equalisation, multi-temporal calibration and absolute calibration. In the end, the dimensioning element for the calibration frequency was found to be the NedT degradation due to the micro-bolometer $1 / \mathrm{f}$ noise. In order to meet the NedT requirement, the blackbody calibration must be carried out every 10 minutes.

It must be noted that the mission definition allows a blackbody calibration per site if the need appears in the course of a more detailed analysis. Indeed, only a limited number of sites are acquired. They are the same throughout the mission's lifetime. If a calibration per site were needed, the data volume does not seem to be a problem either due to the small size of the images.

In contrast, deep space calibration is used to assess emissivity and transmission drift due to the space environment. These parameters vary slowly along the instrument's lifetime, and as a consequence, calibrations can be spaced by up to 1 month. Here again, more frequent calibrations can be foreseen, if need be. However, since the deep space steering is achieved by the satellite and the thermal stability of the instrument is perturbed by the manoeuvre, it is not reasonable to perform more than one deep space calibration per orbit. 


\section{PRELIMINARY PERFORMANCES}

The dimensioning of the instrument was done in synergy with the MTF and the SNR / NedT performance budgets. Indeed the entrance pupil diameter is selected for the instrument to be compliant with both the MTF and the SNR / NedT requirements. The preliminary performance budgets are computed based on models validated through previous projects. The results are detailed in this paragraph.

\subsection{MTF}

The MTF budget includes: optical MTF, detector MTF, smearing and miss-synchronisation. Table 3 summarises the MTF budget for the two instruments: VNIR and TIR. They are computed assuming an entrance pupil diameter of $80 \mathrm{~mm}$ and $270 \mathrm{~mm}$ respectively. These are the minimum diameters required in order to meet the requirement of 0.1 . The MTF figures at the Nyquist frequency are given along-track and across-track.

\begin{tabular}{|c|c|c|c|c|c|}
\hline VNIR Instrument & Blue & Red & NIR1 & NIR2 & Requirement \\
\hline Across-track MTF & 0.19 & 0.25 & 0.28 & 0.29 & $\geq 0.1$ \\
\hline Along-track MTF & 0.12 & 0.18 & 0.21 & 0.21 & $\geq 0.1$ \\
\hline TIR Instrument & TIR1 & TIR2 & TIR3 & TIR4 & Requirement \\
\hline Across-track MTF & 0.21 & 0.20 & 0.22 & 0.22 & $\geq 0.1$ \\
\hline Along-track MTF & 0.12 & 0.12 & 0.13 & 0.13 & $\geq 0.1$ \\
\hline
\end{tabular}

Table 3: Preliminary MTF budget (at the Nyquist frequency)

The optical MTF takes into account the diffraction contributor, driven by the diameter of the entrance pupil and the wavelength. Optical aberrations have also an impact on the MTF and were considered in the budget, in particular the chromatism. In addition, other contributors such as manufacturing defects, misalignments during integration or due to launch and thermo-elastic effects on focusing were included with an experience-based estimated allocation.

The detector MTF contributor is based on measurements.

When imaging in a pushbroom mode with a CCD detector, the smearing is due to the image shift during integration time. This is the case for the VNIR instrument. The smearing contributor to the MTF is 0.64. On the other hand, a microbolometer is used for the TIR instrument. Such detectors act as thermometers with a characteristic time constant, hence they do not react instantaneously to the temperature variations of the scene, creating a smearing effect as well. Thus the micro-bolometer sampling time has to be finely tuned in accordance with its time constant in order to achieve the required MTF.

Mis-synchronisation occurs when binning several acquisitions of the same on-ground pixels taken at different times by different detector pixels. This is the case for the TDI-like binning used by the TIR instrument. This imaging mode requires a precise steering of the satellite line of sight and small optics distortion. The budget takes into account an FTM degradation due to a mis-synchronization of 0.95 , which corresponds to a shift of 0,35 pixels between the first and the last acquisition of the same scene pixel. This figure seems compatible with the Myriade platform capabilities. Finally, optical distortion must be lower than $2 \%$ for 8 TDI images / lines.

\subsection{SNR \& NedT}

The preliminary SNR budged for the VNIR instrument was computed making the following assumptions:

- $\quad$ Optics transmission: 0.90

- $\quad$ Filters transmission: 0.85

- Q Quantum efficiency: 0.63 (Blue) / 0.71 (Red) / 0.43 (NIR1) / 0.25 (NIR2)

- $\quad$ Coding: 14 bits 
The SNR requirement was found to be less dimensioning than the MTF requirement in terms of the entrance pupil diameter. Therefore, the SNR budget for the VNIR instrument has been computed taking into consideration an entrance pupil with a diameter of $80 \mathrm{~mm}$.

Regarding the TIR instrument, the NedT budged has been computed for a different number of TDI-like binned pixels: 2, 4, 8 and 16. This exercise shows a neat improvement of the performances following an increase in the number of binned pixels. However, the TDI-like binning has been limited to 8 pixels to limit the MTF degradation due to missynchronisation. Once this parameter was set, the NedT budget was recalculated for several entrance pupil diameters. The result of this second exercise provides the minimum diameter of $190 \mathrm{~mm}$ in order to meet the NedT requirement of $0.5 \mathrm{~K}$ and the minimum diameter of $300 \mathrm{~mm}$ in order to meet the design goal of $0.2 \mathrm{~K}$. A trade-off led to the current dimensioning with an entrance pupil diameter of $270 \mathrm{~mm}$, the minimum needed to meet the MTF requirement. The preliminary radiometric budget for both VNIR and TIR instruments is shown in Table 4.

\begin{tabular}{|c|c|c|c|c|c|}
\hline VNIR instrument & Blue & Red & NIR1 & NIR2 & Requirement \\
\hline SNR @ the minimum radiance & 120 & 140 & 180 & 70 & $\geq 100$ \\
\hline TIR instrument & TIR1 & TIR2 & TIR3 & TIR4 & Requirement \\
\hline NedT @ 290 K & $0.2 \mathrm{~K}$ & $0.3 \mathrm{~K}$ & $0.5 \mathrm{~K}$ & $0.6 \mathrm{~K}$ & $\leq 0.5 \mathrm{~K}$ \\
\hline
\end{tabular}

Table 4: Preliminary SNR and NedT budgets

The preliminary SNR budget shows that all VNIR bands are compliant with the requirement, except for band NIR2. The non-compliance is due to the lower quantum efficiency of the detector in that spectral region and the narrow bandwidth of the band. However, it is acceptable at mission level to use this band at a lower resolution and therefore improve SNR by binning.

Despite the lower sensitivity of micro-bolometers compared to quantum detectors, the NedT budget shows that the mission requirements can be met with an uncooled detector. The dimensioning of the TIR instrument has been driven by the NedT design goal requirement of $0.2 \mathrm{~K}$ for the priority bands: TIR1 and TIR2. With the proposed instrument, the design goal is met for band TIR1 while bands TIR2 and TIR3 meet the NedT requirement of $0.5 \mathrm{~K}$. Band TIR4 is slightly non-compliant.

\subsection{TIR Absolute calibration, multi-temporal calibration and equalisation}

A preliminary absolute calibration budget was computed based on a model developed for previous projects. Several contributors were taken into account including: the error in the measured radiance, the gain and offset drift between two calibrations, the error due to non-linearity and the error associated to the calibration method and the knowledge of blackbody emissivity and temperature. The absolute calibration budget is shown in Table 5 .

The preliminary multi-temporal calibration budget takes into account the following contributors: the thermistors drifts, the stability of the thermal regulation of the instrument's subassemblies, the error in the knowledge of the temperature and ageing. The multi-temporal calibration performances should be understood as the relative error between absolute calibrations. The multi-temporal calibration budget has been computed at the beginning of life (BOL) and at the end of life (EOL); the results are also shown in Table 5. 
The equalisation performances have also been roughly estimated. The front lens contribution is small; the pixel residual non-uniformity is the major contributor of the present budget as shown in Table 5. The equalisation budget must be further refined.

\begin{tabular}{|l|c|c|c|c|c|}
\hline & TIR1 & TIR2 & TIR3 & TIR4 & Requirement \\
\hline Absolute calibration & $0.42 \mathrm{~K}$ & $0.47 \mathrm{~K}$ & $0.36 \mathrm{~K}$ & $0.38 \mathrm{~K}$ & $\leq 1 \mathrm{~K}$ \\
\hline Multi-temporal calibration (BOL) & $0.19 \mathrm{~K}$ & $0.29 \mathrm{~K}$ & $0.22 \mathrm{~K}$ & $0.23 \mathrm{~K}$ & $\leq 0.5 \mathrm{~K}$ \\
\hline Multi-temporal calibration (EOL) & $0.53 \mathrm{~K}$ & $0.67 \mathrm{~K}$ & $0.56 \mathrm{~K}$ & $0.59 \mathrm{~K}$ & $\leq 0.5 \mathrm{~K}$ \\
\hline Equalisation & $0.04 \mathrm{~K}$ & $0.05 \mathrm{~K}$ & $0.04 \mathrm{~K}$ & $0.04 \mathrm{~K}$ & $\leq 0.5 \mathrm{~K}$ \\
\hline
\end{tabular}

Table 5: Preliminary absolute calibration, multi-temporal calibration and equalisation budgets

The figures presented in this paragraph are closely related to the design of the instrument, in particular the thermal control and the calibration system, and to the calibration method and frequencies. Indeed, these budgets are an important input to be taken into account when designing the instrument.

\section{CONCLUSION}

The present study shows that the MISTIGRI mission can be achieved with an instrumental concept based on an uncooled detector which can be accommodated on a standard Myriade platform. The radiometric requirements for the TIR instrument are very demanding considering the type of instrument. The proposed calibration method has been assessed and seems to be compliant with the mission requirements. In addition, it has been shown that the radiometric performances of the instrument will be closely connected firstly to the thermal stability of the various elements of the camera amd generating a background signal, and secondly the various drifts, in particular due to the detector and video electronics, and thirdly the calibration method and frequency, in order to limit the impact of these background signals and drifts. These three key points which are mutually connected should drive the design of the instrument.

A Mission Definition Review has followed the study presented in this paper. The review was declared successful and it was thus decided to go ahead with the MISTIGRI mission in the frame of a cooperation project, yet to be implemented and possibly between France and Spain. The aim of CNES is to develop a high performance, low-cost system to be launched in 2015. 


\section{REFERENCES}

[1] Agam N., Kustas W.P., Anderson M.C., Li F. and Colaizzi P., "Utility of thermal sharpening over Texas high plains irrigated agricultural fields", J. Geophys. Res., 112, D19110, doi:10.1029/2007JD008407 (2007).

[2] Arnfield A.J., "Two decades of urban climate research: a review of turbulence, exchanges of energy and water, and the urban heat island", Int. J. Climatology, 23, 1, 1-26 (2003).

[3] Boulet G., Chehbouni A., Gentine P., Duchemin B., Ezzahar J. and Hadria R., "Monitoring water stress using time series of observed to unstressed surface temperature difference. Agricultural and Forest Meteorology", 146(3-4): 159172 (2007).

[4] Courault D., Seguin B. and Olioso A. "Review on estimation of evapotranspiration from remote sensing data: From empirical to numerical modeling approaches", Irrigation and Drainage Systems, 19(3-4): 223-249 (2005).

[5] Jacob F., Schmugge T., Olioso A., French A., Courault D., Ogawa K., Petitcolin F., Chehbouni A., Pinheiro A. and Privette J., "Modeling and Inversion in Thermal Infrared Remote Sensing over Vegetated Land Surfaces", Advances in Land Remote Sensing : System, Modeling, Inversion, and Application (ed S. Liang), 354 (Springer, on line): 245-292 (2006).

[6] Kalma J.D., McVicar T.R. and McCabe M.F., "Estimating Land Surface Evaporation: A Review of Methods Using Remotely Sensed Surface Temperature Data", Surveys in Geophysics, 29(4-5): 421-469 (2008).

[7] Kustas W.P., Li F., Jackson T.J., Prueger J.H., MacPherson J.I. and Wolde M., "Effects of remote sensing pixel resolution on modelled energy flux variability of croplands in Iowa", Remote Sens. Environ., 92, 535-547 (2004).

[8] Lagouarde J.P., Ballans H., Moreau P., Guyon D. and Coraboeuf D., "Experimental Study of Brightness Surface Temperature Angular Variations of Maritime Pine (Pinus pinaster) Stands", Remote Sensing of Environment, 72, 1734 (2000).

[9] Lagouarde J.P. and Irvine M., "Directional anisotropy in thermal infrared measurements over Toulouse city centre during the CAPITOUL measurement campaigns: first results", Meteorology and Atmospheric Physics, special issue CAPITOUL. 102, 173-185, DOI: 10.1007/s00703-008-0325-4 (2008).

[10] Schmugge T., French A., Ritchie J., Rango A. and Pelgrum H., "Temperature and emissivity separation from multispectral thermal infrared observations", Remote Sens. Environ. 79:189-198 (2002).

[11] Sobrino J.A., Li Z.L., Stoll M.P. and Becker F., "Improvements in the split-window technique for land surface temperature determination", IEEE Transactions on Geoscience and Remote Sensing, vol. 32, pp. 243-253 (1994).

[12] Voogt J.A. and Oke T.R., "Thermal remote sensing of urban climates", Remote Sens. Environ., 86, 370-384 (2003).

[13] Lagouarde J. P., Kerr Y. H. and Brunet Y., "An experimental study of angular effects on surface temperature for various plant canopies and bare soils", Agricultural and Forest Meteorology 77, no. 3-4: 167-190 (1995). 